\title{
Postoperative remote lung injury and its impact on surgical outcome
}

\author{
Lin Chen ${ }^{1,2+}$, Hailin Zhao $^{2 \dagger}$, Azeem Alam$^{2}$, Emma Mi ${ }^{2}$, Shiori Eguchi ${ }^{2}$, Shanglong Yao ${ }^{1 *}$ and Daqing $\mathrm{Ma}^{2 *}$ (D)
}

\begin{abstract}
Postoperative remote lung injury is a complication following various surgeries and is associated with short and long-term mortality and morbidity. The release of proinflammatory cytokines, damage-associated molecular patterns such as high-mobility group box-1, nucleotide-biding oligomerization domain (NOD)-like receptor protein 3 and heat shock protein, and cell death signalling activation, trigger a systemic inflammatory response, which ultimately results in organ injury including lung injury. Except high financial burden, the outcome of patients developing postoperative remote lung injury is often not optimistic. Several risk factors had been classified to predict the occurrence of postoperative remote lung injury, while lung protective ventilation and other strategies may confer protective effect against it. Understanding the pathophysiology of this process will facilitate the design of novel therapeutic strategies and promote better outcomes of surgical patients. This review discusses the cause and pathology underlying postoperative remote lung injury. Risk factors, surgical outcomes and potential preventative/treatment strategies against postoperative remote lung injury are also addressed.
\end{abstract}

Keywords: Remote lung injury, Cytokine, Pathophysiology, Risk factor, Therapeutic strategy

\section{Background}

There are more than 230 million surgical operations around the world each year [1]. Although surgery is an essential treatment pathway in many diseases, respiratory complications following surgery away from the lung, referred to as 'remote lung injury', are associated with high mortality and physical disability even 5 years post-surgery $[2,3]$. The cost of hospital care associated with such complications is high [4].

Acute lung injury (ALI) and acute respiratory distress syndrome (ARDS) are two common forms of lung injury after surgery. Postoperative remote lung injury affects patient outcomes directly. In this review, the mechanisms of postoperative remote lung injury and its impact on surgical outcomes and prognosis will be discussed. Transfusion is often indispensable in surgery but can have detrimental effects after surgery, including infection

\footnotetext{
*Correspondence: ysltian@163.com; d.ma@imperial.ac.uk

${ }^{+}$Lin Chen and Hailin Zhao contributed equally to this work

'Department of Anaesthesiology, Institute of Anaesthesiology and Critical

Care Medicine, Union Hospital, Tongji Medical College, Huazhong University of Science and Technology, Wuhan 430022, Hubei, China

${ }^{2}$ Anaesthetics, Pain Medicine and Intensive Care, Department of Surgery and Cancer, Faculty of Medicine, Imperial College London, Chelsea \& Westminster Hospital, London SW10 9NH, UK
}

and lung injury. According to the Food and Drug Administration, transfusion related acute lung injury (TRALI) is a severe event especially with platelet or plasma containing transfusions among the elderly [5] which is beyond the scope of this review and will not be discussed.

\section{Epidemiology}

A study carried out by Blum et al. demonstrated that the incidence of ARDS in patients who have undergone non-cardiothoracic surgery is $0.2 \%$ [6]. Kogan et al. conducted a retrospective study on the incidence and mortality of ARDS in patients after cardiac surgery. Although the incidence is low at just $0.61 \%$, the mortality rate is significantly high at $40.5 \%$ [7]. However, others reported that the incidence of ARDS after surgery is as high as $20 \%$ and the mortality rate is up to $80 \%$ [8]. One recent research indicated that the incidence of ARDS is comparable after abdominal surgery and thoracic surgery with incidences of 3.4 and $4.3 \%$ respectively [9]. Although no estimated incidence of ALI has been investigated, a prospective study demonstrated that 1113 out of 6235 patients in the King County Lung Injury Project (KCLIP) cohort suffered from ALI [10]. The observed differences in incidence rate may

(c) The Author(s). 2019 Open Access This article is distributed under the terms of the Creative Commons Attribution 4.0 International License (http://creativecommons.org/licenses/by/4.0/), which permits unrestricted use, distribution, and 
be due to the different in patient population and protocols used. Interestingly, the incidence of ARDS of all causes in Spain and Northern Europe is lower than that in the United States [11, 12]. Although no comparison between different countries has been discussed, the difference in the incidence of ARDS in various countries may also apply to postoperative ARDS.

\section{Mechanisms of postoperative remote lung injury}

Remote lung injury often occurs following major surgery due to traumatic injury to primary organs that triggers systemic inflammation [13] (Fig. 1). Pro-inflammatory cytokines and damage-associated molecular patterns (DAMPs) molecules have been shown to play critical roles in mediating detrimental organ cross-talk during the postoperative period.

\section{Cytokines}

Traumatic tissue injury, for example during surgery, causes the release of inflammatory cytokines locally which then spread systemically and subsequently result in organ injury including lung injury. The release of cytokines can be detected in patients after cardiac surgery. Prondzinsky et al. [14] demonstrated that interleukin-6 (IL-6) in plasma was increased in patients after cardiopulmonary bypass (CPB) surgery. Furthermore, the authors found that the correlation between bypass duration and IL-6 is higher in the CPB-coronary artery bypass graft group than in the CPB-percutaneous coronary intervention group, suggesting that surgical trauma contributed to inflammatory response independent of $\mathrm{CPB}$. An increase in the concentration of IL- $1 \beta$ and IL- 6 following renal ischaemia-reperfusion injury and bilateral nephrectomy had been noted, whilst IL-6 was shown to play a vital role in causing lung injury after acute renal failure [15, 16]. Vlaar et al. [17] reported that "aged" platelet transfusion induced IL-6 release in animal lung tissue, whilst using a "two-hit" model the authors demonstrated that the supernatant of platelet concentrates were responsible for pulmonary inflammation. It has also been shown that TRALI is associated with both systemic and pulmonary inflammation compared to the control cohorts, as indicated by higher levels of IL-6 and IL- 8 in the plasma and bronchoalveolar lavage fluid (BALF) [18, 19].

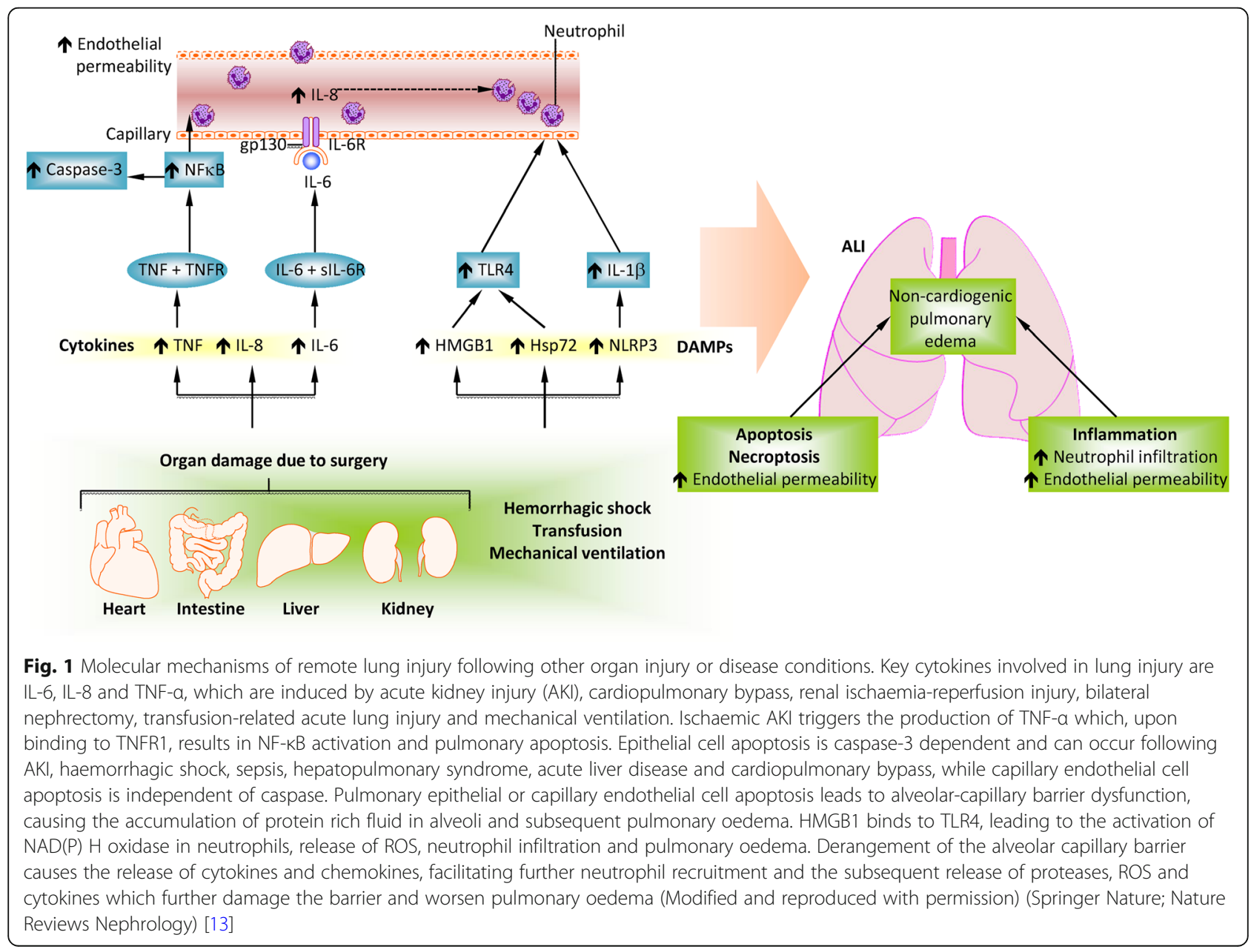




\section{DAMPs}

DAMPs are endogenous mediators that play critical roles in various diseases. It is thought that DAMPs are transported to the lungs via circulation from organs damaged perioperatively. Although the role of DAMPs in lung injury is not completely understood, several well-described DAMPs are involved in the pathogenesis of postoperative remote lung injury $[20,21]$.

\section{High-mobility group box-1 (HMGB1)}

Injured cells and immune cells including macrophages release HMGB1 after surgery, which triggered the production of various pro-inflammatory cytokines. Various surgical procedures, including gastrointestinal surgery and $\mathrm{CPB}$, may induce release of HMGB1 [20, 22]. A study demonstrated that there was an increase in serum HMGB1 after thoracic oesophagectomy, whilst the peak concentration of HMGB1 correlated with length of ICU stay and duration of mechanical ventilation [23]. Moreover, treatment with anti-HMGB1 antibody alleviated lung injury by reducing inflammatory cytokines and inhibiting NF-kB activation [24]. The HMGB1/toll-like receptor 4 (TLR4) signalling pathway had been shown to trigger neutrophil $\mathrm{NAD}(\mathrm{P}) \mathrm{H}$ oxidase activation, which facilitated the release of reactive oxygen species (ROS) [25]. An increase in HMGB1 was also found in ALI induced by liver ischaemia/reperfusion (I/R) injury, whereby binding of HMGB1 to its receptor TLR4 and the subsequent activation of downstream signalling pathways contributed to the development of lung injury [26]. Yamamoto et al. [27] demonstrated that HMGB1 was released into the circulation system after hepatic I/R injury and was related to ALI. Furthermore, they used an HMGB1 absorption column to reduce the concentration of HMGB1 in serum, which attenuated both liver injury and lung injury.

\section{NOD-like receptor protein 3 (NLRP3)}

NLRP3 is a member of the NLR family that participates in inflammatory response under various cellular stresses. Upon activation, an inflammasome complex is formed which facilitates the maturation and secretion of IL-1 $\beta$ and IL-18, mediated by activated caspase-1 [28, 29]. Moreover, the interaction between extracellular histones and NLRP3 inflammation also mediates ALI [30].

NLRP3 expression is increased in the lung following mechanical ventilation. Kuipers et al. [31] demonstrated that $5 \mathrm{~h}$ of mechanical ventilation upregulate NLRP3 mRNA expression in alveolar macrophages from patients. In addition, the increase of NLRP3 mRNA resulted in upregulation of caspase- 1 expression and an increase in uric acid level. Compared to the wild-type group, NLRP3 knock-out mice experienced less lung injury after high tidal volume mechanical ventilation. Mechanistic insight was provided by $\mathrm{Wu}$ et al., they demonstrated that cyclic stretch activated NLRP3 inflammasome and increased IL-1 $\beta$ production in alveolar macrophages, mediated by mitochondria-generated ROS. Moreover, mechanical ventilation was shown to activate NLRP3 inflammasome in mouse alveolar macrophages and increase IL-1 $\beta$ release in vivo. However, pulmonary inflammatory injury induced by mechanical ventilation was alleviated by IL-1 $\beta$ neutralization [21]. The evidence indicated that macrophage NLRP3 inflammasome may bridge the gap between mechanical stretch and the release of IL-1 $\beta$. Recently, it was reported that autophagy in alveolar macrophages contributed to the pathogenesis of lung injury during mechanical ventilation through activation of the NLRP3 inflammasome [32].

Haemorrhagic shock is capable of activating NLRP3 inflammasome. In lung endothelial cells, ROS derived from haemorrhagic shock-activated $\mathrm{NAD}(\mathrm{P}) \mathrm{H}$ oxidase induced inflammasome activation and IL- $1 \beta$ secretion. Inflammasome activation is amplified by ROS released by neutrophils which further enhance $\operatorname{NAD}(\mathrm{P}) \mathrm{H}$ oxidase activation [33]. Imbalance of NLRP3 inflammasome activation and its negative-feedback regulator pryin also contributed to ALI following haemorrhagic shock [34].

\section{Heat shock proteins (Hsp)}

Hsp are another type of DAMPs released by cells under stress and noxious stimuli in a process known as stress protein response (SPR). SPR can be activated by hyperthermia and various environmental insults such as oxidative stress toxins [35]. Increasing evidence indicated that Hsp were involved in the process of lung injury. The presence of extracellular Hsp72 (eHsp72) has been reported in the pulmonary oedema fluid of patients with ALI. In addition, eHsp72 release was found in mice under SPR activation [36]. Chase et al. [37] further validated the relationship between Hsp72 and lung inflammation. Intratracheal instillation of Hsp72 caused TLR-4 dependent cytokine release and neutrophil recruitment in BALF. In vitro, Hsp72 directly activated airway epithelial cells and induced upregulation of IL-8 expression, which was NF- $\mathrm{kB}$ dependent. Hsp70 was able to trigger pro-inflammatory signals in macrophages through toll-like receptors [38]. Various studies have reported that in patients after major surgery, there was an increased release of Hsp70 into the circulation [39-41]. Interestingly, circulating Hsp70 after major surgery was associated with an increased expression of IL-6 in plasma, whilst both were found to be involved in postoperative organ dysfunction [40]. However, the concentration of Hsp70 declined immediately after surgical insult, suggesting that it only initiated injurious processes upon interaction with its receptor. 


\section{Apoptosis and necroptosis}

Apoptosis in inflammatory cells and alveolar cells mediated ALI after haemorrhagic shock [42]. In an indirect ALI mouse model caused by haemorrhagic shock and sepsis, lung inflammation was found to be characterized by caspase- 3 dependent lung epithelial cell apoptosis $[43,44]$. In addition, caspase- 3 dependent pulmonary injury was evident during the pathogenesis of hepatopulmonary syndrome, whilst lung injury secondary to liver injury could be alleviated with administration of caspase-3 inhibitor Z-DEVD-FMK [45]. Pulmonary injury induced by intestinal $I / R$ was also characterized by increased TUNEL positive cells and caspase- 3 activity in the lung [46]. Another study demonstrated that ischaemic acute kidney injury triggered tumor necrosis factor- $\alpha$ (TNF- $\alpha$ ) production which, through binding to its receptor TNFR1, resulted in pulmonary apoptosis by activating NF-kB [47]. However, in term of programmed cell death, pulmonary epithelial and endothelial cells react differently. Barlos et al. proved that apoptosis of epithelial cells was caspase-dependent, whilst endothelial cells underwent apoptosis in an apoptosis-inducing factor-dependent, caspase-independent manner [48]. Surgical operations such as cardiopulmonary bypass may also cause pulmonary inflammatory response. Increased activity of caspase-3 in the lung has been noted during this process [49].

Recently, it was reported that regulated necrosis also participates in remote lung injury. Two different forms of regulated necrosis, necroptosis and parthanatos, were found to be present in lung injury after kidney transplantation in rats. TNF- $\alpha$ was responsible for activation of key elements of necroptosis and parthanatos in lung epithelial cells, whilst blocking their function with inhibitors alleviated remote lung injury [50].

\section{Pathology of postoperative remote lung injury}

Postoperative remote lung injury shares the same pathological changes as ALI/ARDS. ARDS is characterized by increased permeability of the alveolar epithelium and capillary endothelium. The disruption of these barriers results in the accumulation of protein-rich fluid in the alveoli, causing pulmonary oedema.

Taking remote lung injury following kidney surgery as an example, kidney injury after surgical operation causes the release of cytokines and chemokines as well as DAMPs which attract a large number of immune cells, such as polymorphonuclear leukocytes (i.e., neutrophils) and T cells into the alveolar space [13] (Fig. 2). Activated macrophages recruit neutrophils and circulating monocytes to the site of injury in the lung. Neutrophils at injured sites release proteases, ROS and other inflammatory mediators, which further damage the barrier, worsening the pulmonary oedema [51]. Moreover, the inflammatory mediators damage type II pneumocytes, which are responsible for producing surfactant. The destruction of these cells results in an increase in surface tension and subsequent collapse of alveoli [52]. Subsequently, the normal structure of lung tissue is disrupted. The injured lung is characterized by thickened alveolar septa, infiltration of neutrophils even red blood cells in lung tissue as well as the accumulation of protein-rich fluid in the alveolar spaces [13, 53] (Fig. 3). The combination of all these processes leads to impairment of gas exchange between the blood stream and alveolar space, resulting in hypoxemia.

\section{Surgical outcome of patients with postoperative remote lung injury}

Overall surgical outcome for patients who have developed lung injury after surgery is not optimistic. Kinugasa et al. [54] demonstrated that postoperative pulmonary complications (PPC) are directly related to an increase in inpatient deaths within ninety days after oesophagectomy. Patients who developed postoperative pneumonia also had a lower five-year overall survival rate compared to those without $(26.7 \%$ VS $53.4 \%$, hazard ratio $=5.380$ ). Furthermore, pneumonia is one of two independent risk factors to predict poor long-term survival, whilst the other being pathological tumor stage. Another study conducted by Khuri et al. [55] showed that occurrence of pulmonary complications within the first thirty days after major surgery resulted in lower survival rate during the eight-year follow up period.

In a retrospective single centre study conducted in Japan, 502 patients underwent oesophageal carcinoma resection were enrolled and their postoperative complications were analysed [56]. The overall incidence of postoperative complications was $43 \%$ with the incidence of PPC was $19.7 \%$. Importantly, patients who developed PPC experienced a decreased overall survival rate with a multivariable hazard ratio of 1.60 .

Recently, a meta-analysis discussed the relationship between postoperative lung injury and the incidence of mortality and mobility after abdominal or thoracic surgery [9]. Among 3365 patients, the overall incidence of postoperative lung injury was approximately $4 \%$ regardless of types of surgery; however, postoperative lung injury after thoracic surgery was associated with higher patient morbidity. It was found that lung protective ventilation during surgery resulted in a lower incidence of postoperative lung injury, although it has no effect on postoperative mortality. In addition, patients with postoperative lung injury or PPC required longer mechanical ventilation support as well as longer ICU and hospital stay, which contributed towards a higher financial burden on healthcare system $[9,57,58]$. 


\section{Primary Kidney injury}

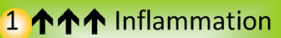

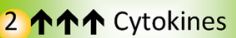

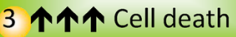

\section{Remote Lung injury}

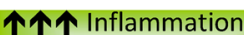

个个 Non-cardiogenic

pulmonary oedema
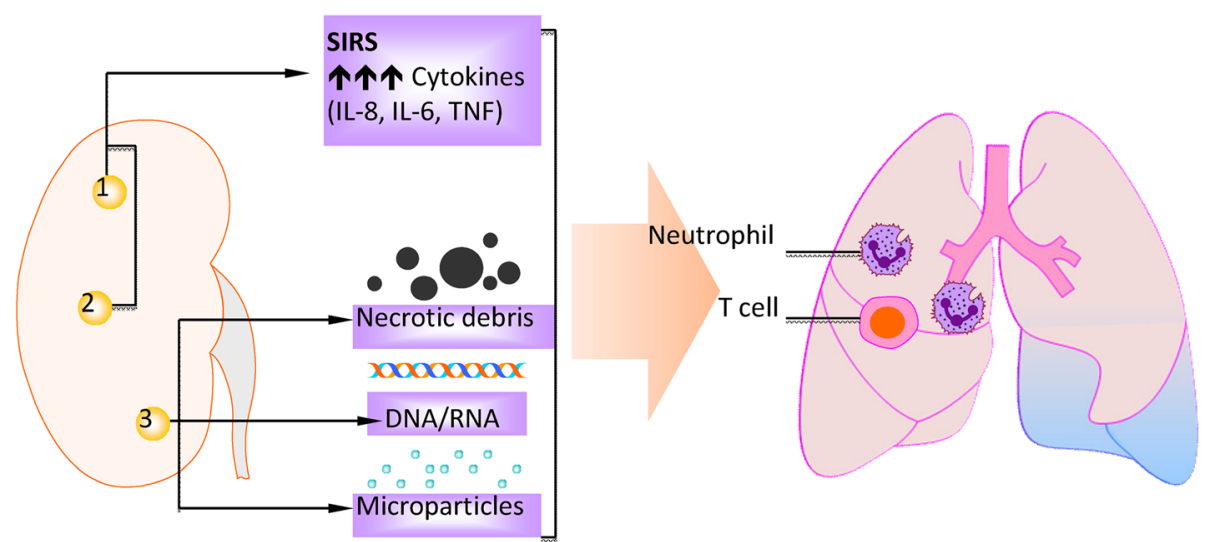

Fig. 2 Primary kidney injury and remote lung injury. Primary kidney injury causes the release of DAMP molecules, which in turn results in the upregulation of inflammatory responses in the distant lung. Immune cells, such as neutrophils, monocytes and T cells, contribute to the exacerbation of remote lung injury (Modified and reproduced with permission) (Springer Nature; Nature Reviews Nephrology) [13]

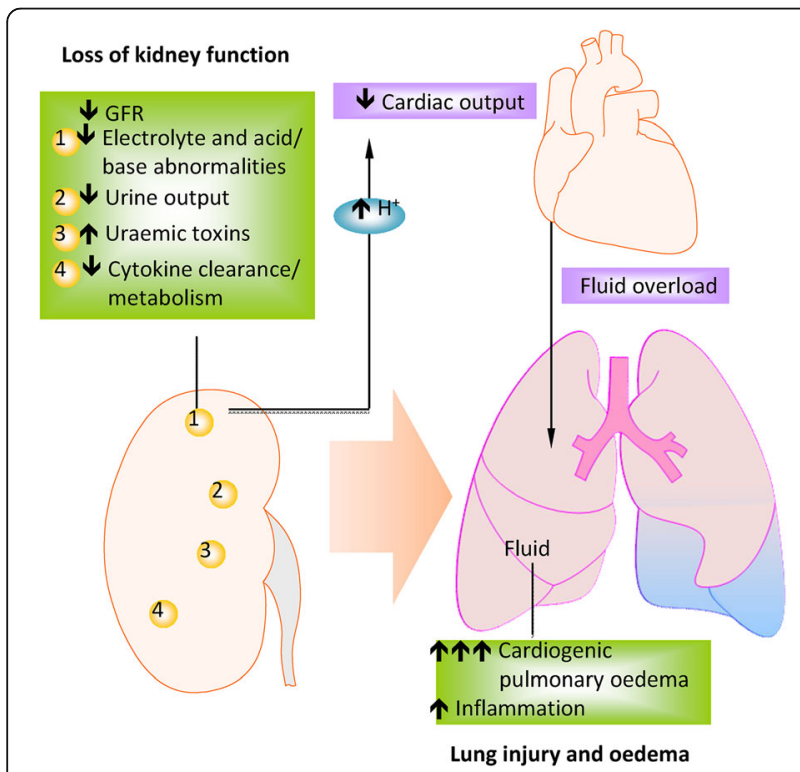

Fig. 3 Lung oedema due to functional loss of kidney. Factors associated with the initiation of remote lung injury include the accumulation of toxic by-products, enhanced cytokine release and impaired metabolism due to an imbalance of mediators secreted in kidney injury. These insults cause an increase in pulmonary vascular permeability and, therefore, oedema. Key cytokines in the pathogenesis of remote lung injury following AKI are IL-6 and IL-8, which lead to endothelial dysfunction and pulmonary oedema (Modified and reproduced with permission) (Springer Nature; Nature Reviews Nephrology) [13]

\section{Predictions and prevention for postoperative remote lung injury}

Postoperative remote lung injury and/or PPC are not uncommon following major surgical procedures $[57,59,60]$. As a result, it is important to be able to predict risk factors and consider appropriate precautions. In 1997, BrooksBrunn analysed data from 400 patients underwent abdominal surgery [61]. Six out of twenty-three risk factors were identified: age over 60, impaired preoperative cognitive function, smoking history within the past 8 weeks, body mass index over 27, history of cancer and the incision-site. In another prospective survey with patients underwent general elective surgery, postoperative nasogastric intubation, preoperative sputum production and longer duration of anaesthesia were identified as modifiable risk factors [60]. Given the high rate of pulmonary complications and the high mortality rates following oesophagectomy, Law et al. [62] analysed data from 421 patients to further investigate potential predictive factors for PPC. Logistic regression analysis identified three predictive factors for PPC: advanced age, operation period and proximal tumor location.

In 2010, a large prospective, multicentre study reported that $5 \%$ of patients developed PPC [1]. Seven independent risk factors were identified, including low preoperative arterial oxygen saturation, acute respiratory infection in the last month, age, preoperative anaemia, upper abdominal or intrathoracic surgery, surgical operation lasting more than $2 \mathrm{~h}$ and emergency surgery. In another multicentre cohort research, Kor et al. [63] 
re-evaluated the risk factors for post-surgical ARDS. In contrast to the previous study in 2010, they found nine independent risk factors contributed to postoperative lung injury: sepsis, high-risk aortic vascular surgery, high-risk cardiac surgery, emergency surgery, cirrhosis, admission locations other than home, increased respiratory rate, $\mathrm{FIO}_{2}$ greater than $35 \%$ and $\mathrm{SpO}_{2}$ less than $95 \%$. This study also indicated that the surgical lung injury prediction (SLIP) score is of inferior power in this high-risk population than SLIP-2, which is more accurate in diverse and acutely ill patients. However, due to variation in clinical settings in different centres, there is still no standardized prediction scale available worldwide. Furthermore, one recent study reported by Fernandez-Bustamante et al. showed that PPCs are common in patients in spite of protective ventilation settings [64]. They also revealed 3 non-modifiable risk factors as emergency, surgical site and age, and 5 modifiable factors of colloid administration, preoperative oxygenation, blood loss, anaesthesia duration and tidal volume. All those risk factors are summarized in the Table 1.

Identification of risk factors allows clinicians to predict postoperative remote lung injury. However, efforts to improve ventilation strategies during surgery are also vital. Amongst patients without ARDS at the onset of ventilation, fewer patients develop lung injury under protective ventilation compared to conventional ventilation [65]. In a population underwent major abdominal surgery, lung protective ventilation during surgery was associated with a lower incidence of PPC and better clinical outcome [66]. Furthermore, Severgnini et al. [67] reported that protective ventilation during abdominal surgery correlated with improved

Table 1 The modifiable and non-modifiable factors in prediction of postoperative remote lung injury

\begin{tabular}{|c|c|c|}
\hline & Modifiable factors & Non-modifiable factors \\
\hline $\begin{array}{l}\text { Preoperative } \\
\text { variables }\end{array}$ & $\begin{array}{l}\text { Anaemia } \\
\mathrm{FIO}_{2} \text { greater than 35\% } \\
\text { Impaired cognitive } \\
\text { function } \\
\text { Increased respiratory rate } \\
\text { Low arterial oxygen } \\
\text { saturation } \\
\mathrm{SpO}_{2} \text { less than 95\% } \\
\text { Sputum production }\end{array}$ & $\begin{array}{l}\text { Acute respiratory infection } \\
\text { in the last month } \\
\text { Advanced age } \\
\text { Admission locations other } \\
\text { than home } \\
\text { BMl over } 27 \\
\text { Cirrhosis } \\
\text { History of cancer } \\
\text { Sepsis } \\
\text { Smoking history within } \\
\text { the past } 8 \text { weeks }\end{array}$ \\
\hline $\begin{array}{l}\text { Intraoperative } \\
\text { varibles }\end{array}$ & $\begin{array}{l}\text { Anaesthesia duration } \\
\text { Blood loss } \\
\text { Colloid administration } \\
\text { Operation period } \\
\text { Tidal volume }\end{array}$ & $\begin{array}{l}\text { Emergency surgery } \\
\text { High-risk aortic vascular } \\
\text { surgery } \\
\text { High-risk cardiac surgery } \\
\text { Proximal tumor location } \\
\text { Surgical site } \\
\text { Upper abdominal or } \\
\text { intrathoracic surgery }\end{array}$ \\
\hline $\begin{array}{l}\text { Postoperative } \\
\text { variables }\end{array}$ & Nasogastric intubation & \\
\hline
\end{tabular}

$\mathrm{BMI}$ body mass index, $\mathrm{FIO}_{2}$ fraction of inspiration $\mathrm{O}_{2}, \mathrm{SpO}_{2}$ peripheral capillary oxygen saturation pulmonary function after surgery. A meta-analysis by Serpa Neto et al. [68] reported that patients ventilated with low tidal volume (VT) are less likely to develop PPC. While another large RCT compared the effect of high or low positive end expiratory pressure (PEEP) on PPC occurrence [69], surprisingly, the strategized combination of high PEEP and recruitment manoeuvres failed to protect against PPC. The authors, therefore, suggested that intraoperative protective ventilation should consist of a low VT and low PEEP without recruitment manoeuvres. Patients may respond to the same ventilation strategy and the same presumed protective ventilation strategy (low VT with high PEEP) may produce controversial results. Different from the result from the PROVHILO trial [68], Spadaro et al. showed that low VT together with PEEP at $10 \mathrm{~cm} \mathrm{H}_{2} \mathrm{O}$ is protective during one lung ventilation [70].

\section{Therapeutic strategies}

In recent years there has been an increasing understanding of the possible pathophysiological processes underlying the development of postoperative remote lung injury, with evidence to suggest that it may be possible to exploit this knowledge to reduce its incidence within the clinical environment.

In vivo models of ARDS have demonstrated that various anaesthetic agents, including isoflurane, sevoflurane and desflurane, possess anti-inflammatory and cytoprotective effects [71-73]. These data suggest that volatile anaesthetic agents may possess significant protective effects in ameliorating ARDS as a result of a variety of pathogenic insults. Whilst there is limited clinical evidence specifically purporting the protective effects of these agents against postoperative remote lung injury, given the fact that the various insults studied share common pathogenic pathways with remote lung injury, it is reasonable to ascertain that these volatile anaesthetic agents may too be protective against remote lung injury.

Isoflurane is a commonly used volatile anaesthetic agent [74] and has been shown to possess both anti-inflammatory [75] and cytoprotective [76] properties. Animal models of lung injury, including mechanical ventilation induced lung injury and inhaled endotoxin [71, 77], have demonstrated the potential utility of isoflurane as a pulmonary protectant. Proposed mechanisms include the downregulation of NF-kB by reducing its expression and simultaneously upregulating $\mathrm{I}-\mathrm{kB}$ expression, whilst also mediating the expression of apoptotic markers, including Bcl-2 and Bax [78, 79], as well as a reduction in vascular leak [71]. Furthermore, isoflurane also attenuated LPS-induced lung injury by inhibiting NLRP3 inflammasome activation [80]. The fact that isoflurane attenuates the activation of common inflammatory pathways suggests that the perioperative attenuation of these pro-inflammatory mediators in patients 
undergoing surgery may reduce the incidence of remote lung injury.

Sevoflurane, another commonly used inhaled anaesthetic agent, has similarly been demonstrated the ability to ameliorate lung injury in vivo. In animal models of lung injury, sevoflurane has consistently demonstrated its protective properties by reducing deleterious histological changes, reducing wet to dry ratio and improving ventilation parameters [81-83]. Furthermore, sevoflurane administration caused a reduction in neutrophil infiltration, pro-inflammatory cytokine release as well as a reduction in NF- $\mathrm{KB}$ expression $[84,85]$. The release of inflammatory cytokines has been shown to be involved in the pathogenesis of remote lung injury, once against suggesting that the use of sevoflurane may similarly reduce the incidence of remote pulmonary insults following surgery.

Propofol has been shown to reduce the expression of a similar cytokine profile to sevoflurane, thus conferring a 2 -fold increase in survival in an LPS model of lung injury by reducing pulmonary oedema and histological damage via its anti-inflammatory and anti-oxidative properties [86, 87]. Dexmedetomidine (Dex) is a sedative that has been demonstrated anti-inflammatory effects and the ability to ameliorate lung injury. Dex is a potent and highly selective $\alpha 2$-adrenergic agonist that exhibits sedative, analgesic, amnestic, and sympatholytic properties. Previous studies have demonstrated that Dex was able to protect against lung injury following kidney ischaemiareperfusion injury due to its ant-inflammatory effects [88] and ability to reduce pulmonary microvascular hyper-permeability [89]. Furthermore, Dex reduced caspase 3 and Bax expression, whilst upregulated $\mathrm{Bcl}-2$ expression. As animal studies have indicated the significant role of caspase 3 dependent lung epithelial cell apoptosis in the pathogenesis of remote lung injury [42, 43], including hepatopulmonary syndrome, Dex's anti-inflammatory effects may reduce the incidence of post-operative remote lung injury in clinical practice but warrant further study.

Another therapeutic approach may be the use of xenon, a novel general anaesthetic agent, that has demonstrated anti-inflammatory and anti-apoptotic effects in models of acute lung injury following renal injury [90].

Furthermore, numerous observational studies have attributed the judicious use of intravenous fluid in the perioperative period with a higher incidence of acute lung injury $[91,92]$. One randomized clinical trial conducted by Volta CA et al. showed that patients received balanced solutions experienced lower concentration of active matrix metalloproteinase- 9 and higher level of tissue inhibitor of metalloproteinase- 1 and IL-10 compared to the unbalanced solutions [93]. Whilst a large RCT of patients with acute lung injury found that conservative administration of intravenous fluids is associated with an improvement in oxygenation, lung compliance and 60-day survival [94]. This is a potentially simple way of reducing the incidence of perioperative lung injury, however must be balanced with the risks associated with dehydration.

\section{Remaining questions and directions for future research}

Whilst the scope for improvement in the incidence of postoperative remote lung injury is significant, there are a number of important unanswered questions. Currently, the vast majority of evidence underlying our current understanding of the pathogenesis of remote lung injury is through in vivo studies, with limited human studies.

The off-license use of anaesthetic agents to ameliorate remote lung injury is inherently associated with risks in terms of safety and efficacy. Only a few human studies exist investigating the therapeutic effects of sevoflurane and propofol in ameliorating postoperative lung injury, with no overall significant identified differences in the incidence of ARDS, as well as conflicting biochemical changes reported between the studies [95-97]. However, historical evidence exists to suggest that inhaled agents, such as isoflurane, may possess deleterious effects [98].

This highlights the importance of high-powered, controlled, clinical trials investigating previously purported in vivo markers of remote lung injury, such as IL-6, HMGB-1 and NF- $\mathrm{kB}$, in human subjects. The aim of this should be to facilitate similarly high-powered, randomised controlled trials investigating the efficacy, safety and side-effect profiles of anaesthetic agents such as isoflurane, sevoflurane and dexmedetomidine within clinical practice, as well as conservative approaches such as non-judicious intravenous fluid administration. Furthermore, additional in vitro and in vivo research is required to investigate the development of novel agents targeting specific pro-inflammatory markers, such as HMGB-1, NLRP3 and Hsp, as these agents may confer additional therapeutic benefit in the future.

\section{Conclusion}

Postoperative remote lung injury is not an uncommon condition clinically, and it is associated with adverse effects on overall patient survival. The pathological mechanisms are complex, involving cytokines and DAMPs released by injured organs or surgical sites. As a result, the normal function of the respiratory system is compromised, contributing to the development of lung injury. Due to the poor outcome associated with postoperative remote lung injury, predicting the population at risk is critical in order to facilitate lung injury prevention at the incipient stage. Approaches to ameliorate the pathological effects of postoperative remote lung injury are still required and necessitate further investigation, 
particularly utilizing well-powered, randomized controlled trials.

\section{Abbreviations}

ALI: Acute lung injury; ARDS: Acute respiratory distress syndrome; BALF: Bronchoalveolar lavage fluid; CPB: Cardiopulmonary bypass; DAMPs: Damage-associated molecular patterns; HMGB1: High-mobility group box-1; HSP: Heat shock protein; I/R: Ischaemia/reperfusion; IL: Interleukin; NLRP3: NOD-like receptor protein 3; PEEP: Positive end expiratory pressure; PPC: Postoperative pulmonary complication; ROS: Reactive oxygen species; SLIP: Surgical lung injury prediction; SPR: Stress protein response; TLR4: Tolllike receptor 4; TNF-a: Tumor necrosis factor-a; TRALI: Transfusion related acute lung injury; VT: Tidal volume

\section{Acknowledgements}

Not applicable.

\section{Funding}

The work was supported by the Medical Research Council, The Developmental Pathway Funding Scheme program (project grant G802392), BJA/RCoA Research Fellowship grant, London, UK and the Basic and Frontier Research Fund (DM) and National Natural Science Foundation of China (No. 81671890) (SLY). The funders have no role in regarding study design, data collection, analysis and manuscript preparation.

\section{Availability of data and materials}

All data generated or analysed during this study are included in this published article.

\section{Authors' contributions}

LC and HZ conducted the literature search and analysed the data and wrote the draft. AA, EM and SE helped review all the literature included and share critical viewpoint on the manuscript. SLY and DM oversaw this project and revised the manuscript. All authors read and approved the final manuscript.

\section{Ethics approval and consent to participate}

Not applicable.

\section{Consent for publication}

Not applicable.

\section{Competing interests}

Daqing $\mathrm{Ma}$ is an editorial board member for BMC Anesthesiology. The other authors declare that they have no competing interests.

\section{Publisher's Note}

Springer Nature remains neutral with regard to jurisdictional claims in published maps and institutional affiliations.

Received: 20 November 2018 Accepted: 18 February 2019 Published online: 04 March 2019

\section{References}

1. Canet J, Gallart L, Gomar C, Paluzie G, Valles J, Castillo J, et al. Prediction of postoperative pulmonary complications in a population-based surgical cohort. Anesthesiology. 2010;113(6):1338-50.

2. Fernandez-Perez ER, Sprung J, Afessa B, Warner DO, Vachon CM, Schroeder $\mathrm{DR}$, et al. Intraoperative ventilator settings and acute lung injury after elective surgery: a nested case control study. Thorax. 2009;64(2):121-7.

3. Herridge MS, Tansey CM, Matte A, Tomlinson G, Diaz-Granados N, Cooper A, et al. Functional disability 5 years after acute respiratory distress syndrome. N Engl J Med. 2011;364(14):1293-304.

4. Dimick JB, Chen SL, Taheri PA, Henderson WG, Khuri SF, Campbell DJ. Hospital costs associated with surgical complications: a report from the private-sector National Surgical Quality Improvement Program. J Am Coll Surg. 2004;199(4):531-7.

5. Menis M, Anderson SA, Forshee RA, McKean S, Johnson C, Warnock R, et al. Transfusion-related acute lung injury and potential risk factors among the inpatient US elderly as recorded in Medicare claims data, during 2007 through 2011. Transfusion. 2014;54(9):2182-93.
6. Blum JM, Stentz MJ, Dechert R, Jewell E, Engoren M, Rosenberg AL, et al. Preoperative and intraoperative predictors of postoperative acute respiratory distress syndrome in a general surgical population. Anesthesiology. 2013;118(1):19-29.

7. Kogan A, Preisman S, Levin S, Raanani E, Sternik L. Adult respiratory distress syndrome following cardiac surgery. J Card Surg. 2014;29(1):41-6.

8. Stephens RS, Shah AS, Whitman GJ. Lung injury and acute respiratory distress syndrome after cardiac surgery. Ann Thorac Surg. 2013;95(3):1122-9.

9. Serpa NA, Hemmes SN, Barbas CS, Beiderlinden M, Fernandez-Bustamante A, Futier $\mathrm{E}$, et al. Incidence of mortality and morbidity related to postoperative lung injury in patients who have undergone abdominal or thoracic surgery: a systematic review and meta-analysis. Lancet Respir Med. 2014:2(12):1007-15.

10. Rubenfeld GD, Caldwell E, Peabody E, Weaver J, Martin DP, Neff M, et al. Incidence and outcomes of acute lung injury. N Engl J Med. 2005:353(16): 1685-93.

11. Luhr OR, Antonsen K, Karlsson M, Aardal S, Thorsteinsson A, Frostell CG, et al. Incidence and mortality after acute respiratory failure and acute respiratory distress syndrome in Sweden, Denmark, and Iceland. The ARF study group. Am J Respir Crit Care Med. 1999;159(6):1849-61.

12. Villar J, Blanco J, Anon JM, Santos-Bouza A, Blanch L, Ambros A, et al. The ALIEN study: incidence and outcome of acute respiratory distress syndrome in the era of lung protective ventilation. Intensive Care Med. 2011;37(12):1932-41.

13. Faubel $\mathrm{S}$, Edelstein $\mathrm{CL}$. Mechanisms and mediators of lung injury after acute kidney injury. Nat Rev Nephrol. 2016;12(1):48-60

14. Prondzinsky R, Knupfer A, Loppnow H, Redling F, Lehmann DW, Stabenow I, et al. Surgical trauma affects the proinflammatory status after cardiac surgery to a higher degree than cardiopulmonary bypass. J Thorac Cardiovasc Surg. 2005;129(4):760-6.

15. Klein CL, Hoke TS, Fang WF, Altmann CJ, Douglas IS, Faubel S. Interleukin-6 mediates lung injury following ischemic acute kidney injury or bilateral nephrectomy. Kidney Int. 2008;74(7):901-9.

16. Hoke TS, Douglas IS, Klein CL, He Z, Fang W, Thurman JM, et al. Acute renal failure after bilateral nephrectomy is associated with cytokine-mediated pulmonary injury. J Am Soc Nephrol. 2007;18(1):155-64.

17. Vlaar AP, Hofstra JJ, Kulik W, van Lenthe H, Nieuwland R, Schultz MJ, et al. Supernatant of stored platelets causes lung inflammation and coagulopathy in a novel in vivo transfusion model. Blood. 2010;116(8):1360-8.

18. Vlaar AP, Hofstra JJ, Determann RM, Veelo DP, Paulus F, Levi M, et al. Transfusion-related acute lung injury in cardiac surgery patients is characterized by pulmonary inflammation and coagulopathy: a prospective nested case-control study. Crit Care Med. 2012;40(10):2813-20.

19. Roubinian NH, Looney MR, Kor DJ, Lowell CA, Gajic O, Hubmayr RD, et al. Cytokines and clinical predictors in distinguishing pulmonary transfusion reactions. Transfusion. 2015;55(8):1838-46.

20. Haque A, Kunimoto F, Narahara H, Okawa M, Hinohara H, Kurabayashi M, et al. High mobility group box 1 levels in on and off-pump cardiac surgery patients. Int Heart J. 2011;52(3):170-4.

21. Wu J, Yan Z, Schwartz DE, Yu J, Malik AB, Hu G. Activation of NLRP3 inflammasome in alveolar macrophages contributes to mechanical stretchinduced lung inflammation and injury. J Immunol. 2013;190(7):3590-9.

22. Lin GX, Wang T, Chen MH, Hu ZH, Ouyang W. Serum high-mobility group box 1 protein correlates with cognitive decline after gastrointestinal surgery. Acta Anaesthesiol Scand. 2014;58(6):668-74.

23. Suda K, Kitagawa Y, Ozawa S, Saikawa Y, Ueda M, Abraham E, et al. Serum concentrations of high-mobility group box chromosomal protein 1 before and after exposure to the surgical stress of thoracic esophagectomy: a predictor of clinical course after surgery? Dis Esophagus. 2006;19(1):5-9.

24. Kim JY, Park JS, Strassheim D, Douglas I, Diaz DVF, Asehnoune K, et al. HMGB1 contributes to the development of acute lung injury after hemorrhage. Am J Physiol Lung Cell Mol Physiol. 2005;288(5):L958-65.

25. Fan J, Li Y, Levy RM, Fan JJ, Hackam DJ, Vodovotz Y, et al. Hemorrhagic shock induces $N A D(P) H$ oxidase activation in neutrophils: role of HMGB1TLR4 signaling. J Immunol. 2007;178(10):6573-80.

26. Yang Z, Deng Y, Su D, Tian J, Gao Y, He Z, et al. TLR4 as receptor for HMGB1-mediated acute lung injury after liver ischemia/reperfusion injury. Lab Investig. 2013;93(7):792-800.

27. Yamamoto T, Ono T, Ito T, Yamanoi A, Maruyama I, Tanaka T. Hemoperfusion with a high-mobility group box 1 adsorption column can prevent the occurrence of hepatic ischemia-reperfusion injury in rats. Crit Care Med. 2010;38(3):879-85. 
28. Leemans JC, Cassel SL, Sutterwala FS. Sensing damage by the NLRP3 inflammasome. Immunol Rev. 2011;243(1):152-62.

29. Latz E, Xiao TS, Stutz A. Activation and regulation of the inflammasomes. Nat Rev Immunol. 2013;13(6):397-411.

30. Grailer JJ, Canning BA, Kalbitz M, Haggadone MD, Dhond RM, Andjelkovic $A V$, et al. Critical role for the NLRP3 inflammasome during acute lung injury. J Immunol. 2014;192(12):5974-83.

31. Kuipers MT, Aslami H, Janczy JR, van der Sluijs KF, Vlaar AP, Wolthuis EK, et al. Ventilator-induced lung injury is mediated by the NLRP3 inflammasome. Anesthesiology. 2012;116(5):1104-15.

32. Zhang Y, Liu G, Dull RO, Schwartz DE, Hu G. Autophagy in pulmonary macrophages mediates lung inflammatory injury via NLRP3 inflammasome activation during mechanical ventilation. Am J Physiol Lung Cell Mol Physiol. 2014;307(2):L173-85.

33. Xiang M, Shi X, Li Y, Xu J, Yin L, Xiao G, et al. Hemorrhagic shock activation of NLRP3 inflammasome in lung endothelial cells. J Immunol. 2011;187(9): 4809-17.

34. Xu P, Wen Z, Shi X, Li Y, Fan L, Xiang M, et al. Hemorrhagic shock augments Nlrp3 inflammasome activation in the lung through impaired pyrin induction. J Immunol. 2013;190(10):5247-55.

35. Muralidharan S, Mandrekar P. Cellular stress response and innate immune signaling: integrating pathways in host defense and inflammation. J Leukoc Biol. 2013;94(6):1167-84.

36. Ganter MT, Ware LB, Howard M, Roux J, Gartland B, Matthay MA, et al. Extracellular heat shock protein 72 is a marker of the stress protein response in acute lung injury. Am J Physiol Lung Cell Mol Physiol. 2006;291(3):L354-61.

37. Chase MA, Wheeler DS, Lierl KM, Hughes VS, Wong HR, Page K. Hsp72 induces inflammation and regulates cytokine production in airway epithelium through a TLR4- and NF-kappaB-dependent mechanism. J Immunol. 2007;179(9):6318-24.

38. Bulut $Y$, Michelsen KS, Hayrapetian L, Naiki Y, Spallek R, Singh M, et al. Mycobacterium tuberculosis heat shock proteins use diverse toll-like receptor pathways to activate pro-inflammatory signals. J Biol Chem. 2005;280(22):20961-7.

39. Dybdahl B, Wahba A, Lien E, Flo TH, Waage A, Qureshi N, et al. Inflammatory response after open heart surgery: release of heat-shock protein 70 and signaling through toll-like receptor-4. Circulation. 2002; 105(6):685-90.

40. Kimura F, Itoh H, Ambiru S, Shimizu H, Togawa A, Yoshidome H, et al. Circulating heat-shock protein 70 is associated with postoperative infection and organ dysfunction after liver resection. Am J Surg. 2004;187(6):777-84.

41. Szerafin T, Hoetzenecker K, Hacker S, Horvath A, Pollreisz A, Arpad P, et al. Heat shock proteins 27, 60, 70, 90alpha, and 20 s proteasome in on-pump versus off-pump coronary artery bypass graft patients. Ann Thorac Surg. 2008;85(1):80-7.

42. Jernigan TW, Croce MA, Fabian TC. Apoptosis and necrosis in the development of acute lung injury after hemorrhagic shock. Am Surg. 2004;70(12):1094-8.

43. Perl M, Chung CS, Perl U, Lomas-Neira J, de Paepe M, Cioffi WG, et al. Fasinduced pulmonary apoptosis and inflammation during indirect acute lung injury. Am J Respir Crit Care Med. 2007;176(6):591-601.

44. Perl M, Chung CS, Perl U, Thakkar R, Lomas-Neira J, Ayala A. Therapeutic accessibility of caspase-mediated cell death as a key pathomechanism in indirect acute lung injury. Crit Care Med. 2010;38(4):1179-86.

45. Chen B, Ning JL, Gu JT, Cui J, Yang Y, Wang Z, et al. Caspase-3 inhibition prevents the development of hepatopulmonary syndrome in common bile duct ligation rats by alleviating pulmonary injury. Liver Int. 2015;35(4): 1373-82.

46. Wang G, Chen Z, Zhang F, Jing H, Xu W, Ning S, et al. Blockade of PKCbeta protects against remote organ injury induced by intestinal ischemia and reperfusion via a p66shc-mediated mitochondrial apoptotic pathway. Apoptosis. 2014;19(9):1342-53.

47. White LE, Santora RJ, Cui Y, Moore FA, Hassoun HT. TNFR1-dependent pulmonary apoptosis during ischemic acute kidney injury. Am J Physiol Lung Cell Mol Physiol. 2012;303(5):L449-59.

48. Barlos D, Deitch EA, Watkins AC, Caputo FJ, Lu Q, Abungu B, et al. Traumahemorrhagic shock-induced pulmonary epithelial and endothelial cell injury utilizes different programmed cell death signaling pathways. Am J Physiol Lung Cell Mol Physiol. 2009;296(3):L404-17.

49. Siepe M, Goebel U, Mecklenburg A, Doenst T, Benk C, Stein P, et al. Pulsatile pulmonary perfusion during cardiopulmonary bypass reduces the pulmonary inflammatory response. Ann Thorac Surg. 2008;86(1):115-22.
50. Zhao H, Ning J, Lemaire A, Koumpa FS, Sun JJ, Fung A, et al. Necroptosis and parthanatos are involved in remote lung injury after receiving ischemic renal allografts in rats. Kidney Int. 2015;87(4):738-48.

51. Windsor AC, Mullen PG, Fowler AA, Sugerman HJ. Role of the neutrophil in adult respiratory distress syndrome. Br J Surg. 1993;80(1):10-7.

52. Han S, Mallampalli RK. The acute respiratory distress syndrome: from mechanism to translation. J Immunol. 2015;194(3):855-60.

53. Qiang Y, Liang G, Yu L. Human amniotic mesenchymal stem cells alleviate lung injury induced by ischemia and reperfusion after cardiopulmonary bypass in dogs. Lab Investig. 2016;96(5):537-46.

54. Kinugasa S, Tachibana M, Yoshimura H, Ueda S, Fujii T, Dhar DK, et al. Postoperative pulmonary complications are associated with worse shortand long-term outcomes after extended esophagectomy. J Surg Oncol. 2004;88(2):71-7.

55. Khuri SF, Henderson WG, DePalma RG, Mosca C, Healey NA, Kumbhani DJ. Determinants of long-term survival after major surgery and the adverse effect of postoperative complications. Ann Surg. 2005;242(3):326-41 discussion 341-3.

56. Baba Y, Yoshida N, Shigaki H, Iwatsuki M, Miyamoto Y, Sakamoto Y, et al. Prognostic impact of postoperative complications in 502 patients with surgically resected esophageal squamous cell carcinoma: a retrospective single institution study. Ann Surg. 2016;264(2):305-11.

57. Damian D, Esquenazi J, Duvvuri U, Johnson JT, Sakai T. Incidence, outcome, and risk factors for postoperative pulmonary complications in head and neck cancer surgery patients with free flap reconstructions. J Clin Anesth. 2016;28:12-8.

58. Shander A, Fleisher LA, Barie PS, Bigatello LM, Sladen RN, Watson CB. Clinica and economic burden of postoperative pulmonary complications: patient safety summit on definition, risk-reducing interventions, and preventive strategies. Crit Care Med. 2011;39(9):2163-72.

59. LAS VEGAS investigators. Epidemiology, practice of ventilation and outcome for patients at increased risk of postoperative pulmonary complications: LAS VEGAS - an observational study in 29 countries. Eur J Anaesthesiol. 2017; 34(8):492-507.

60. Mitchell CK, Smoger SH, Pfeifer MP, Vogel RL, Pandit MK, Donnelly PJ, et al. Multivariate analysis of factors associated with postoperative pulmonary complications following general elective surgery. Arch Surg. 1998;133(2): 194-8.

61. Brooks-Brunn JA. Predictors of postoperative pulmonary complications following abdominal surgery. Chest. 1997;111(3):564-71.

62. Law S, Wong KH, Kwok KF, Chu KM, Wong J. Predictive factors for postoperative pulmonary complications and mortality after esophagectomy for cancer. Ann Surg. 2004;240(5):791-800.

63. Kor DJ, Lingineni RK, Gajic O, Park PK, Blum JM, Hou PC, et al. Predicting risk of postoperative lung injury in high-risk surgical patients: a multicenter cohort study. Anesthesiology. 2014;120(5):1168-81.

64. Fernandez-Bustamante A, Frendl G, Sprung J, Kor DJ, Subramaniam B, Martinez $\mathrm{RR}$, et al. Postoperative pulmonary complications, early mortality, and hospital stay following noncardiothoracic surgery: a multicenter study by the perioperative research network investigators. JAMA Surg. 2017;152(2):157-66.

65. Serpa NA, Cardoso SO, Manetta JA, Pereira VG, Esposito DC, Pasqualucci $\mathrm{MO}$, et al. Association between use of lung-protective ventilation with lower tidal volumes and clinical outcomes among patients without acute respiratory distress syndrome: a meta-analysis. JAMA. 2012;308(16):1651-9.

66. Futier E, Constantin JM, Paugam-Burtz C, Pascal J, Eurin M, Neuschwander A et al. A trial of intraoperative low-tidal-volume ventilation in abdominal surgery. N Engl J Med. 2013;369(5):428-37.

67. Severgnini P, Selmo G, Lanza C, Chiesa A, Frigerio A, Bacuzzi A, et al. Protective mechanical ventilation during general anesthesia for open abdominal surgery improves postoperative pulmonary function. Anesthesiology. 2013;118(6):1307-21.

68. Serpa NA, Hemmes SN, Barbas CS, Beiderlinden M, Biehl M, Binnekade JM, et al. Protective versus conventional ventilation for surgery: a systematic review and individual patient data meta-analysis. Anesthesiology. 2015; 123(1):66-78,

69. Hemmes SN, Gama DAM, Pelosi P, Schultz MJ. High versus low positive end-expiratory pressure during general anaesthesia for open abdominal surgery (PROVHILO trial): a multicentre randomised controlled trial. Lancet. 2014;384(9942):495-503

70. Spadaro S, Grasso S, Karbing DS, Fogagnolo A, Contoli M, Bollini G, et al. Physiologic evaluation of ventilation perfusion mismatch and respiratory 
mechanics at different positive end-expiratory pressure in patients undergoing protective one-lung ventilation. Anesthesiology. 2018;128(3):531-8.

71. Englert JA, Macias AA, Amador-Munoz D, Pinilla VM, Isabelle C, Guan J, et al. Isoflurane ameliorates acute lung injury by preserving epithelial tight junction integrity. Anesthesiology. 2015;123(2):377-88.

72. Wagner J, Strosing KM, Spassov SG, Lin Z, Engelstaedter H, Tacke S, et al. Sevoflurane posttreatment prevents oxidative and inflammatory injury in ventilator-induced lung injury. PLoS One. 2018;13(2):e0192896.

73. Lin X, Ju YN, Gao W, Li DM, Guo CC. Desflurane attenuates ventilatorinduced lung injury in rats with acute respiratory distress syndrome. Biomed Res Int. 2018;2018:7507314

74. Pang YL, Chen BS, Li SP, Huang CC, Chang SW, Lam CF, et al. The preconditioning pulmonary protective effect of volatile isoflurane in acute lung injury is mediated by activation of endogenous iNOS. J Anesth. 2012; 26(6):822-8.

75. Collange O, Charles AL, Noll E, Bouitbir J, Zoll J, Piquard F, et al. Isoflurane anesthesia preserves liver and lung mitochondrial oxidative capacity after gut ischemia-reperfusion. Anesth Analg. 2011;113(6):1438-41.

76. Kim M, Kim M, Park SW, Pitson SM, Lee HT. Isoflurane protects human kidney proximal tubule cells against necrosis via sphingosine kinase and sphingosine-1-phosphate generation. Am J Nephrol. 2010;31(4):353-62.

77. Strosing KM, Faller S, Gyllenram V, Engelstaedter H, Buerkle H, Spassov S, et al. Inhaled anesthetics exert different protective properties in a mouse model of ventilator-induced lung injury. Anesth Analg. 2016;123(1):143-51.

78. Li JT, Wang H, Li W, Wang LF, Hou LC, Mu JL, et al. Anesthetic isoflurane posttreatment attenuates experimental lung injury by inhibiting inflammation and apoptosis. Mediat Inflamm. 2013;2013:108928.

79. Wang H, Fan J, Li NL, Li JT, Yuan SF, Yi J, et al. A subanesthetic dose of isoflurane during postconditioning ameliorates zymosan-induced neutrophil inflammation lung injury and mortality in mice. Mediat Inflamm. 2013;2013: 479628.

80. Yin N, Peng Z, Li B, Xia J, Wang Z, Yuan J, et al. Isoflurane attenuates lipopolysaccharide-induced acute lung injury by inhibiting ROS-mediated NLRP3 inflammasome activation. Am J Transl Res. 2016;8(5):2033-46.

81. Casanova J, Garutti I, Simon C, Giraldez A, Martin B, Gonzalez G, et al. The effects of anesthetic preconditioning with sevoflurane in an experimental lung autotransplant model in pigs. Anesth Analg. 2011;113(4):742-8.

82. Otsuki T, Ishikawa M, Hori Y, Goto G, Sakamoto A. Volatile anesthetic sevoflurane ameliorates endotoxin-induced acute lung injury via microRNA modulation in rats. Biomed Rep. 2015;3(3):408-12.

83. Luo C, Yuan D, Zhao W, Chen H, Luo G, Su G, et al. Sevoflurane ameliorates intestinal ischemia-reperfusion-induced lung injury by inhibiting the synergistic action between mast cell activation and oxidative stress. Mol Med Rep. 2015;12(1):1082-90.

84. Voigtsberger S, Lachmann RA, Leutert AC, Schlapfer M, Booy C, Reyes L, et al. Sevoflurane ameliorates gas exchange and attenuates lung damage in experimental lipopolysaccharide-induced lung injury. Anesthesiology. 2009; 111(6):1238-48.

85. Ferrando C, Aguilar G, Piqueras L, Soro M, Moreno J, Belda FJ. Sevoflurane, but not propofol, reduces the lung inflammatory response and improves oxygenation in an acute respiratory distress syndrome model: a randomised laboratory study. Eur J Anaesthesiol. 2013;30(8):455-63.

86. Zhao LL, Hu GC, Zhu SS, Li JF, Liu GJ. Propofol pretreatment attenuates lipopolysaccharide-induced acute lung injury in rats by activating the phosphoinositide-3-kinase/Akt pathway. Braz J Med Biol Res. 2014;47(12):1062-7.

87. Yao W, Luo G, Zhu G, Chi X, Zhang A, Xia Z, et al. Propofol activation of the Nrf2 pathway is associated with amelioration of acute lung injury in a rat liver transplantation model. Oxidative Med Cell Longev. 2014;2014:258567.

88. Gu J, Chen J, Xia P, Tao G, Zhao H, Ma D. Dexmedetomidine attenuates remote lung injury induced by renal ischemia-reperfusion in mice. Acta Anaesthesiol Scand. 2011;55(10):1272-8.

89. Chen Q, Yi B, Ma J, Ning J, Wu L, Ma D, et al. alpha2-adrenoreceptor modulated FAK pathway induced by dexmedetomidine attenuates pulmonary microvascular hyper-permeability following kidney injury. Oncotarget. 2016;7(35):55990-6001.

90. Zhao $H$, Huang $H$, Ologunde R, Lloyd DG, Watts $H$, Vizcaychipi MP, et al. Xenon treatment protects against remote lung injury after kidney transplantation in rats. Anesthesiology. 2015;122(6):1312-26.

91. Evans RG, Naidu B. Does a conservative fluid management strategy in the perioperative management of lung resection patients reduce the risk of acute lung injury? Interact Cardiovasc Thorac Surg. 2012;15(3):498-504.
92. Chau EH, Slinger P. Perioperative fluid management for pulmonary resection surgery and esophagectomy. Semin Cardiothorac Vasc Anesth. 2014;18(1):36-44.

93. Volta CA, Trentini A, Farabegoli L, Manfrinato MC, Alvisi V, Dallocchio F, et al. Effects of two different strategies of fluid administration on inflammatory mediators, plasma electrolytes and acid/base disorders in patients undergoing major abdominal surgery: a randomized double blind study. J Inflamm (Lond). 2013;10(1):29.

94. Wiedemann HP, Wheeler AP, Bernard GR, Thompson BT, Hayden D, DeBoisblanc $B$, et al. Comparison of two fluid-management strategies in acute lung injury. N Engl J Med. 2006:354(24):2564-75.

95. Potocnik I, Novak JV, Sostaric M, Jerin A, Stupnik T, Skitek M, et al. Antiinflammatory effect of sevoflurane in open lung surgery with one-lung ventilation. Croat Med J. 2014;55(6):628-37.

96. Erturk E, Topaloglu S, Dohman D, Kutanis D, Besir A, Demirci Y, et al. The comparison of the effects of sevoflurane inhalation anesthesia and intravenous propofol anesthesia on oxidative stress in one lung ventilation. Biomed Res Int. 2014;2014:360936.

97. Feng $H$, Wang GM, Qiao Y, Zhao X, Liu DY, Ding YL, et al. Effects of sevoflurane preconditioning on lung injury during one lung ventilation. Int J Clin Exp Med. 2015;8(8):13634-8.

98. Hung CJ, Liu FY, Shaiu YC, Kao A, Lin CC, Lee CC. Assessing transient pulmonary injury induced by volatile anesthetics by increased lung uptake of technetium-99m hexamethylpropylene amine oxime. Lung. 2003;181(1):1-7.
Ready to submit your research? Choose BMC and benefit from:
- fast, convenient online submission
- thorough peer review by experienced researchers in your field
- rapid publication on acceptance
- support for research data, including large and complex data types
- gold Open Access which fosters wider collaboration and increased citations
- maximum visibility for your research: over $100 \mathrm{M}$ website views per year
At BMC, research is always in progress.
Learn more biomedcentral.com/submissions 